Article

\title{
Effect of Dietary Supplementation of Moringa Oleifera on the Production Performance and Fecal Methanogenic Community of Lactating Dairy Cows
}

\author{
Lifeng Dong ${ }^{\circledR}$, Tingting Zhang and Qiyu Diao* \\ Beijing Key Laboratory for Dairy Cow Nutrition, Sino-US Joint Lab on Nutrition and Metabolism of Ruminants, \\ Feed Research Institute, Chinese Academy of Agricultural Sciences, Key Laboratory of Feed Biotechnology of \\ the Ministry of Agriculture, Beijing 100081, China; donglifeng@caas.cn (L.D.); tingting5_2_0@163.com (T.Z.) \\ * Correspondence: diaoqiyu@caas.cn; Tel.: +86-010-82106055
}

Received: 25 February 2019; Accepted: 20 May 2019; Published: 22 May 2019

check for updates

Simple Summary: High-quality forages such as protein-rich ingredients are essential to maximize production performance in dairy production. However, enteric methane produced by methanogenesis represents a substantial waste of feed energy for ruminants. Thus, it is important to evaluate the environmental effect when such feed ingredients are used to provide necessary nutrients. The aim of the present study was to examine the effects of dietary supplementation of Moringa oleifera on the production performance and fecal methanogenic community in lactating cows. The study's main results suggest that inclusion of Moringa oleifera improved milk fat content and changed the composition and diversity of methanogens. This study indicates that secondary metabolites from Moringa oleifera may regulate fermentation conditions and associations between some methanogens and other microbes. These findings provide basic information on the utilization of alternative forage resources for dairy cows and can help to better understand the regulation of microbial metabolic function and methane emissions.

\begin{abstract}
Development of alternative forage resources is of great importance to provide necessary nutrients and minimize greenhouse gas emissions in ruminant production. The aim of this study was to examine the effects of dietary supplementation of Moringa oleifera on the production performance and fecal methanogenic community in dairy cows using methyl-coenzyme M reductase $\alpha$-subunit gene. Sixty-four cows were allocated to one of four treatments: basal diet without $M$. oleifera (control) or low $(3 \% w / w, \mathrm{M} 3)$, medium $(6 \%, \mathrm{M} 6)$, or high $(9 \%, \mathrm{M} 9)$ supplementation with M. oleifera. This study demonstrated that different supplementation levels of Moringa oleifera in the diet achieved similar feed intake and milk production, but adding $6 \%$ of Moringa oleifera improved milk fat content. Two families, two phyla, three genera, and three species in total were identified among the four treatments. The fecal archaeal community in the control treatment was predominated by Methanobrevibacter (39.1\% of the total sequence reads) followed by Methanosphaera and Methanocorpusculum at the genus level. The increased abundance of the Methanosphaera genus and Methanosphaera sp. ISO3-F5 species was induced by secondary metabolites of Moringa oleifera in the diet. Results indicated that Moringa oleifera supplementation not only improved dairy product quality but could also potentially reduce methane emissions.
\end{abstract}

Keywords: Moringa oleifera; fecal methanogenic community; dairy cows; $m c r$ A gene sequencing technique

\section{Introduction}

Forage source and nutrient composition hold significant importance for dairy production systems due to the constant cost of commercial concentrates. This cost is a serious constraint for smallholder 
farms when the dietary protein sources are restricted or the cost is unaffordable. In the past few decades, many efforts have been made to explore less-expensive ingredients such as agricultural by-products, tree foliage, and plant leaves to supply adequate nutrients [1].

As an indigenous native tree in the Himalayas, Moringa oleifera $(M$. oleifera) is a perennial leafy tree that produces a high biomass in a short period and is widely distributed in tropical and subtropical areas around the world [2]. Recently, it has been increasingly considered as an alternative ingredient for animal feed because of its high content of protein, vitamins, and minerals. The average crude protein (CP) contents of M. oleifera range from 180 to $270 \mathrm{~g} \mathrm{CP} / \mathrm{kg} \mathrm{DM}$, similar to that of sesame meal (260 g CP/kg DM) [1]. In addition, saponins, tannins, and polysaccharides in M. oleifera demonstrate beneficial anti-inflammatory, antioxidant, and antimicrobial activities and can increase milk yield when dairy cows are offered dried or fresh leaves and soft twigs [3,4]. A recent study [5] found that alfalfa hay and maize silage can be partially replaced by M. oleifera silage without negative effects on nutrient digestibility and milk yield. This enhanced production performance was due to the considerable amounts of secondary metabolites in M. oleifera, which were also used as a potential feed additive to reduce greenhouse gas (GHG) emission of ruminants.

Methane $\left(\mathrm{CH}_{4}\right)$ emission from ruminants is a major contributor to atmospheric $\mathrm{CH}_{4}$ accumulation. Reduction of ruminal $\mathrm{CH}_{4}$ emissions would thus improve energy utilization efficiency and alleviate environmental issues within the dairy industry. For example, ruminal $\mathrm{CH}_{4}$ emissions were significantly decreased when $M$. oleifera leaves were used in an in vitro experiment [6]. Similarly, supplementation of pomegranate pulp in the diet decreased enteric $\mathrm{CH}_{4}$ emissions in dairy cows [7]. These reductions in $\mathrm{CH}_{4}$ emissions were attributed to the direct reduction of ruminal methanogenesis by active polyphenolic compounds either in M. oleifera leaves or pomegranate pulp. However, the variation and responses of fecal methanogenic community to M. oleifera supplementation in the diet of dairy cows have not been elucidated.

Archaeal methanogens are obligate anaerobes that use methanogenesis pathways to facilitate fiber digestion by converting hydrogen into $\mathrm{CH}_{4}$. Daquiado et al. [8] found the predominant species in rumen fluid and manure was Methanobrevibacter ruminantium (63.6\% and $62.4 \%$, respectively), whereas Methanocorpusculum labreanum was most abundant in rectal dung for beef cattle (53.2\%). In addition, the community structures of fecal microbiota reflect not only animal productivity but also health and food safety. Jin et al. [9] found that dietary supplementation of active dried yeast significantly increased the relative abundance of Methanocorpuschulum and Thermoplasma species but decreased Methanobrevibacter in the feces. Mohammadzadeh et al. [10] observed a decrease in the fecal methanogenic archaea abundance in goats when the diet changed from alfalfa hay to a combination of alfalfa hay and oats. Determining the fecal methanogen composition would help us understand the effect of dietary supplementation on methanogenesis and $\mathrm{CH}_{4}$ emissions. Therefore, the objective of the present study was to determine the effect of dietary supplementation of $M$. oleifera on the production performance and on the population and diversity of the fecal methanogenic community in lactating Holsteins dairy cows.

\section{Materials and Methods}

This study was conducted at the Guoxiu dairy farm located in Boading, China (latitude: $38^{\circ} 45^{\prime} 54^{\prime \prime}$ and longitude: $\left.115^{\circ} 08^{\prime} 06^{\prime \prime}\right)$ in 2017 . The experiment design and animal care and handling procedures were evaluated and approved by the Animal Ethics Committee of the Chinese Academy of Agricultural Sciences (protocol number 023-2017) prior to the commencement of the experiment.

\subsection{Animals and Experimental Design}

Sixty-four multiparous lactating Holstein dairy cows (120 \pm 8.0 days in milk; $31.9 \pm 1.20 \mathrm{~kg} /$ day of milk yield at the beginning of the trial) were used in this experiment. Animals were randomly assigned to one of four treatments: (1) control, basal diet without M. oleifera; (2) a low supplementation of $M$. oleifera (3\% w/w; M3); (3) medium supplementation of M. oleifera (6\% w/w; M6); (4) high 
supplementation of $M$. oleifera (9\% w/w; M9). The basal diet was formulated to be isoenergetic and isonitrogenous to meet the nutrient requirements of lactating dairy cows (NY/T 34-2004, Table 1). The treatments were balanced for milk yield, body weight, and lactation period. Rachises and twigs of M. oleifera at 56 days of age were harvested in Guangdong, China $\left(23^{\circ} 8^{\prime} \mathrm{N}, 113^{\circ} 17^{\prime} \mathrm{E}\right)$; these materials were then chopped and dried on plastic sheets for 3 days for further preparation of a total mixed ration (TMR) diet. The CP, neutral detergent fiber (NDF) and acid detergent fiber (ADF) content of M. oleifera were $71.5,743$ and $552 \mathrm{~g} / \mathrm{kg} \mathrm{DM}$, respectively, while the ether extract (EE) and ash content was 48.6 and $78.3552 \mathrm{~g} / \mathrm{kg} \mathrm{DM}$, respectively. The TMR diet was offered ad libitum in amounts resulting in 5\% refusals. The whole experiment (77 days) consisted of 14 days for adaptation to the diet and 63 days for feeding period, with fecal samples collected in the last 5 days of the feeding period. Animals were fed with TMR at 07:00 and 19:00 and milked twice at 06:00 and 16:00 on a daily basis. Cows were housed in individual tie-stalls in a barn with good ventilation and had continuous access to water throughout the experiment. Artificial light was provided by suspended bulbs, and the floor was cleaned twice daily for good hygiene.

Table 1. Ingredients and nutrient composition of the experimental diets.

\begin{tabular}{|c|c|c|c|c|}
\hline \multirow{2}{*}{ Items } & \multicolumn{4}{|c|}{ Dietary Moringa Oleifera Content } \\
\hline & $\mathbf{0}$ & $3 \%$ & $6 \%$ & $9 \%$ \\
\hline \multicolumn{5}{|l|}{ Ingredients, $\%$ of DM } \\
\hline Ground corn & 21.2 & 21.7 & 22.1 & 22.7 \\
\hline Soybean meal & 10.5 & 11.6 & 12.7 & 13.8 \\
\hline DDGS & 8.4 & 8.4 & 8.4 & 8.4 \\
\hline Cottonseed meal & 7.5 & 7.5 & 7.5 & 7.5 \\
\hline Palm fat & 7.5 & 7.5 & 7.5 & 7.5 \\
\hline Beet pulp & 4.7 & 4.7 & 4.7 & 4.7 \\
\hline Alfalfa hay & 20.5 & 17.1 & 13.7 & 10.2 \\
\hline Corn silage & 16.8 & 15.7 & 14.5 & 13.4 \\
\hline Moringa oleifera & 0.0 & 3.0 & 6.0 & 9.0 \\
\hline Premix $^{1}$ & 2.0 & 2.0 & 2.0 & 2.0 \\
\hline Sodium hydrogen carbonate & 0.6 & 0.6 & 0.6 & 0.6 \\
\hline Calcium hydrogen phosphate & 0.2 & 0.2 & 0.2 & 0.2 \\
\hline Sodium chloride & 0.3 & 0.3 & 0.3 & 0.3 \\
\hline \multicolumn{5}{|l|}{ Nutrient composition $^{2}$} \\
\hline $\mathrm{CP}$ & 178.70 & 179.00 & 179.30 & 179.60 \\
\hline $\mathrm{EE}$ & 44.80 & 46.90 & 48.80 & 50.90 \\
\hline Ash & 76.80 & 84.60 & 73.50 & 79.20 \\
\hline NDF & 437.00 & 434.30 & 431.70 & 428.60 \\
\hline $\mathrm{ADF}$ & 211.30 & 214.30 & 217.20 & 219.30 \\
\hline $\mathrm{NE}_{\mathrm{L}}, \mathrm{MJ} / \mathrm{kg}$ & 6.60 & 6.61 & 6.62 & 6.63 \\
\hline
\end{tabular}

${ }^{1}$ One kilogram of premix contained the following: 100,000 IU VA; 40,000 IU VD; $1000 \mathrm{IU}$ VE; $330 \mathrm{mg} \mathrm{Fe;} 250 \mathrm{mg} \mathrm{Cu}$; $400 \mathrm{mg} \mathrm{Mn} ; 500 \mathrm{mg} \mathrm{Zn;} 10 \mathrm{mg} \mathrm{Se} ; 10 \mathrm{mg} \mathrm{I} ; 5 \mathrm{mg} \mathrm{Co}{ }^{2}$ All values were measured from the monthly total mixed ration (TMR) samples, while $\mathrm{NE}_{\mathrm{L}}$ (net energy for lactation) was calculated based on Ministry of Agriculture (MOA) of P.R. China individual feedstuffs recommendations based on chemical composition (MOA, 2004).

\subsection{Sample Collection and Measurements}

Samples of M. oleifera, TMR, and refusals were collected daily. All samples were composited and analyzed for DM (65 ${ }^{\circ} \mathrm{C}$ in a forced-air oven to a constant weight), CP (method 990.03; AOAC International, 2016), ADF and NDF (Ankom200 Fiber Analyzer, Ankom Technology, Macedon, NY, USA). Ash and EE concentration was determined with method 942.05 (AOAC International, 2016) [11]. Milk samples were recorded in the last 5 days of the feeding period and treated with 2-bromo-2-nitropropane-1-2-diol for determination of milk protein, fat, lactose, and total solids. 
Energy-corrected milk yield (ECM), standardized to $4.0 \%$ fat and $3.3 \%$ protein, was calculated using the equation below:

$$
\operatorname{ECM}(\mathrm{kg} / \mathrm{cow} \text { per day })=\text { mikl yield }(\mathrm{kg} / \mathrm{d}) \times \frac{376 \times \text { fat } \%+209 \times \text { protein } \%+948}{3138} .
$$

Rectal fecal samples (200 g per sampling) were collected four times a day (08:00, 12:00, 16:00, and 20:00) and bulked per animal according to institutional animal care guidelines. Fecal samples were stored at $-20{ }^{\circ} \mathrm{C}$ for later DNA extraction, high-throughput sequencing, and bioinformatics analysis.

\subsection{DNA Extraction and High-Throughput Sequencing using McrA Gene}

Fecal samples were freeze-dried, and total DNA was extracted from $200 \mathrm{mg}$ samples with a QIAamp Fast DNA Stool Mini Kit (QIAGEN, CA, USA) according to the manufacturer's instructions. DNA extracts were dissolved in $200 \mu \mathrm{L}$ elution buffer and the quality and quantity of the extracted DNA were determined using a NanoDrop ND-1000 Spectrophotometer (Nyxor Biotech, Paris, France). The PCR primers used to amplify the mcrA fragments were from those of Luton et al. [12]: 5'-GGTGGTGTMGGATTCACACARTAYGCWACAGC-3' (forward) and 5'-TTCATTGCRTAGTTWGGRTAGTT-3' (reverse). The PCR was performed using the TaKaRa rTaq DNA Polymerase system and $2 \mu \mathrm{L}$ of $10 \times$ buffer, $2 \mu \mathrm{L}$ of deoxynucleotide triphosphate (dNTPs) mixture $(2.5 \mathrm{mmol} / \mathrm{L}), 0.2 \mu \mathrm{L}$ of rTaq polymerase, and $0.8 \mu \mathrm{L}$ of each primer (forward and reverse). This reaction mixture $(25 \mu \mathrm{L})$ used the following program: $95^{\circ} \mathrm{C}$ for $3 \mathrm{~min}$, followed by 30 cycles of $95^{\circ} \mathrm{C}$ for $30 \mathrm{~s}, 55^{\circ} \mathrm{C}$ for $30 \mathrm{~s}$, and $72{ }^{\circ} \mathrm{C}$ for $45 \mathrm{~s}$, and a final extension of $72{ }^{\circ} \mathrm{C}$ for $10 \mathrm{~min}$. PCR products were electrophoresed in $1 \%$ agarose in Tris-acetate-EDTA buffer and visualized with ethidium bromide staining. Amplicons were extracted from 1\% agarose gels and purified using the AxyPrep DNA Gel Extraction Kit (Axygen Biosciences, CA, USA) according to the manufacturer's instructions and quantified using QuantiFluor-ST (Promega, Madison, WI, USA). Purified amplicons were then paired-end sequenced $(2 \times 300)$ on an Illumina MiSeq platform according to standard protocols.

\subsection{Bioinformatics Analysis of the Sequence Data}

In the present study, raw FASTQ files were demultiplexed and quality-filtered with the following criteria: (i) The 300-bp reads were truncated at any site that had an average quality score $<20$ over a 50-bp sliding window, and truncated reads $<50 \mathrm{bp}$ were discarded; (ii) exact barcode matching was required, and any 2-nucleotide mismatch in primer matching and reads containing ambiguous characters were removed; and (iii) only sequences that overlapped by more than $10 \mathrm{bp}$ were assembled according to their overlap sequences. The length of over $89 \%$ of the total valid sequence was between 421 and $440 \mathrm{bp}$, while around 10\% of sequences were ranged between 441 and $460 \mathrm{bp}$. Operational taxonomic units (OTUs) were clustered with $97 \%$ similarity cutoff using Uparse algorithm (version 7.1, http://drive5.com/uparse/), and chimeric sequences were identified and removed using UCHIME. The taxonomy of each mcrA gene sequence was analyzed by the RDP Classifier against the FunGene Database using a confidence threshold of $70 \%$ [13]. Good's coverage and rarefaction curves were determined to estimate the coverage and sampling effort. QIIME (version 1.17) was also used to calculate the archaeal population diversity (Simpson's diversity index), evenness (Shannon's diversity index), and richness (Chao1 and Ace index). Venn diagram was constructed according to Oliveros [14] to show the shared and unique OTUs among samples. Heatmap analysis and identification of significant features were also used to determine changes among samples. The data obtained in the present study have been submitted to NCBI (submission ID: SUB 3898364, BioProject ID: PRJNA449795). 


\subsection{Statistical Analyses}

Data were analyzed using SPSS software (version 22.0 for Windows, SPSS Inc., Chicago, IL, USA). Dietary DM intake, milk yield, ECM and milk composition were analyzed the using one-way ANOVA package. The model used was as follows:

$$
\mathrm{Y}_{i j}=\mu+\mathrm{A}_{i}+\mathrm{T}_{j}+\mathrm{e}_{i j}
$$

where $Y_{i}=$ the observations for the dependent variable, $\mu=$ overall mean, $\mathrm{A}_{i}=$ the random animal effect, $\mathrm{T}_{j}=$ the fixed effect of the $j$ th Moringa oleifera amount (treatment, $j=3,6$, or $9 \% w / w$ ), and $e_{i j}=$ the random residual assumed to be normally distributed with mean zero.

Relative abundance data of fecal methanogenic archaea are presented as percentages/proportions. These data were analyzed using Welch's t-test package, and the model was as follows:

$$
\mathrm{Y}_{i j}=\mu+\mathrm{S}_{i}+\mathrm{T}_{j}+\mathrm{e}_{i j}
$$

where $Y_{i}=$ the observations for the dependent variable, $\mu=$ overall mean, $S_{i}=$ the random effect of sampling, $\mathrm{T}_{j}=$ the fixed effect of treatment $j$, and $e_{i j}=$ the random residual assumed to be normally distributed with mean zero.

Treatment means were considered statistically different at $p<0.05$, and SEM values are presented with $p$ values.

\section{Results}

\subsection{Feed Intake and Milk Yield and Composition}

The DM intake, milk yield, and ECM were similar among the four treatments (Table 2). For the milk composition, fat content $(38.2 \mathrm{~g} / \mathrm{kg})$ was highest in the M6 treatment $(p<0.05)$ compared with the other three treatments. Protein, lactose, and total solid content did not differ significantly among the 4 treatments.

Table 2. Effects of supplementation of Moringa oleifera rachises and twigs on the dry matter intake, milk

\begin{tabular}{|c|c|c|c|c|c|c|}
\hline \multirow{2}{*}{ Item $^{1}$} & \multicolumn{4}{|c|}{ Treatment $^{2}$} & \multirow{2}{*}{ SEM $^{3}$} & \multirow{2}{*}{$p$-Value } \\
\hline & Control & M3 & M6 & M9 & & \\
\hline DM intake, $\mathrm{kg} /$ day & 20.6 & 20.9 & 20.7 & 19.3 & 0.53 & 0.09 \\
\hline Milk yield, kg/day & 29.6 & 29.7 & 31.0 & 28.6 & 0.46 & 0.46 \\
\hline ECM kg/day & 31.7 & 32.2 & 34.5 & 31.4 & 0.57 & 0.69 \\
\hline \multicolumn{7}{|l|}{ Milk composition, $\%$} \\
\hline Fat & $3.54^{b}$ & $3.62^{b}$ & $3.82^{\mathrm{a}}$ & $3.68^{a b}$ & 0.07 & 0.04 \\
\hline Protein & 3.65 & 3.70 & 3.66 & 3.70 & 0.03 & 0.49 \\
\hline Lactose & 5.10 & 5.08 & 5.08 & 5.05 & 0.03 & 0.14 \\
\hline Total solid & 13.0 & 13.1 & 13.2 & 13.1 & 0.08 & 0.13 \\
\hline
\end{tabular}
yield and composition of Holstein dairy cows.

${ }^{1} \mathrm{DM}=$ dry matter; ${ }^{2} \mathrm{M} 3, \mathrm{M} 6$, and M9 = dietary Moringa oleifera supplementation of $3 \%, 6 \%$, and $9 \%$ w $w$; Means within rows lacking common superscript differ $(p<0.05) ;{ }^{3}$ SEM $=$ standard error of means.

\subsection{Composition and Dynamics of Fecal Methanogen Community}

A total of 450,500 high-quality sequences with an average length of $439.5 \mathrm{bp}$ were obtained. The Good's coverage indices obtained from each treatment were all above 0.999 , indicating a high-quality of sampling and sequencing. The richness and diversity indices obtained for fecal samples of cows fed different levels of $M$. oleifera are presented in Table 3. Richness indices after the 4 treatments did not differ significantly, although the control group had relatively higher values of Ace and Chao (21.05 and 20.63). By contrast, Shannon's index was highest for the M9 group $(1.783 ; p<0.05)$ and 
similar among the control, M3, and M6 groups (1.653, 1.438, and 1.628, respectively). The Simpson index was lowest for the M9 group $(p<0.05)$ and did not differ significantly among the control, M3, and M6 groups.

Table 3. Effects of supplementation of Moringa oleifera rachises and twigs on the diversity indices of fecal methanogenic archaea based on $m c r$ A gene sequences of lactating Holstein dairy cows.

\begin{tabular}{|c|c|c|c|c|c|c|}
\hline \multirow{2}{*}{ Item $^{1}$} & \multicolumn{4}{|c|}{ Treatment $^{2}$} & \multirow{2}{*}{ SEM $^{3}$} & \multirow{2}{*}{$p$-Value } \\
\hline & Control & M3 & M6 & M9 & & \\
\hline Ace & 21.05 & 19.78 & 15.30 & 14.35 & 1.788 & 0.510 \\
\hline Chao & 20.63 & 19.25 & 19.75 & 18.25 & 0.569 & 0.561 \\
\hline Shannon & $1.653^{b}$ & $1.438^{b}$ & $1.628^{b}$ & $1.783^{\mathrm{a}}$ & 0.0570 & 0.019 \\
\hline Simpson & $0.310^{\mathrm{a}}$ & $0.393^{\mathrm{a}}$ & $0.328^{a}$ & $0.265^{b}$ & 0.0199 & 0.014 \\
\hline
\end{tabular}

${ }^{1}$ Indices of Ace, Chao, Shannon, and Simpson were calculated to measure alpha diversity of the methanogens in the sample; ${ }^{2}$ M3, M6, and M9 = dietary Moringa oleifera supplementation of 3\%, $6 \%$, and $9 \% w / w$; Means within rows lacking common superscript differ $(p<0.05) ;{ }^{3} \mathrm{SEM}=$ standard error of means.

A Venn diagram constructed using the OTUs for the sequences from the fecal samples is presented in Figure 1. Shared and unique OTUs were represented at a $97 \%$ similarity level among the 4 treatments. A total of 51, 50, 48, and 50 OTUs were found for the control, M3, M6, and M9 treatments, respectively, and 38 OTUs were common to all 4 treatments. In pairwise comparisons of treatments, 43 OTUs were shared between the M3 and M6 treatments, 41 between the M6 and M9 treatments, and 41 between the M3 and M9 treatments. Between the control and treatment M3, M6, or M9, respectively, 47, 44, and 44 OTUs were shared. In addition, a heatmap was constructed to determine the relationship between OTUs and experimental treatments based on the log-transformed sequence abundance and is presented based on the species level at the $97 \%$ similarity level (Figure 2). The heatmap showed a change in the abundance of Methanosphaera sp. ISO3-F5, Methanobrevibacter ruminantium, and Methanobrevibacter SM9, indicating that supplementation of $M$. oleifera in the diet resulted in archaeal populations distinct from the control, the same as shown in the abundance analysis.

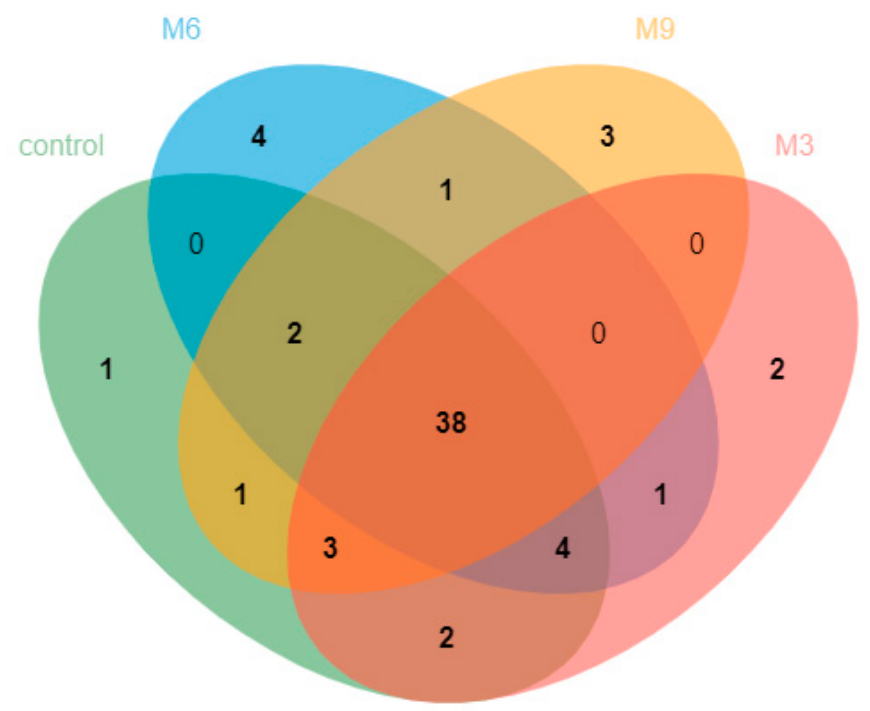

Figure 1. Venn diagram representation of the shared and exclusive Operational taxonomic units (OTUs) at 97\% similarity level of four groups: Control (without Moringa oleifera supplementation), M3 (a low dose of Moringa oleifera supplementation, 3\% w/w), M6 (a medium dose of Moringa oleifera supplementation, $6 \% w / w$ ), M9 (a high dose of Moringa oleifera supplementation, $9 \% w / w$ ) in lactating Holstein dairy cows. 


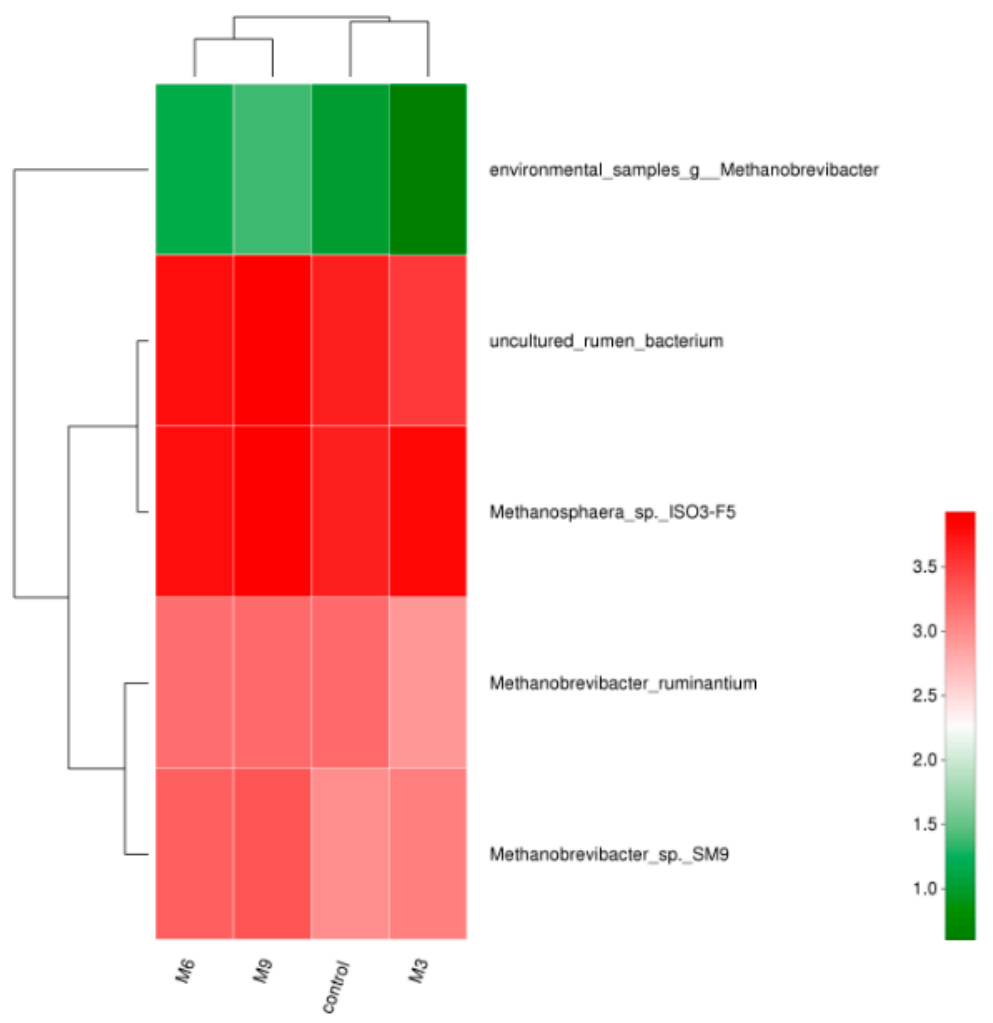

Figure 2. Heatmap under the species level of the four treatments of the lactating Holstein dairy cows fecal sample (control: without Moringa oleifera supplementation; M3: a low dose of Moringa oleifera supplementation, 3\% w/w; M6: a medium dose of Moringa oleifera supplementation, $6 \%$ w/w; M9: a high dose of Moringa oleifera supplementation, $9 \% w / w)$.

The relative abundance of fecal methanogenic archaea in the dairy cows with different supplements of M. oleifera based on the mcrA gene sequencing is listed by taxonomic level in Table 4; three phyla, four orders, four families, five genera, and seven species were determined. The predominant archaeal family across the four treatments in the order Methanobacteriales was Methanobacteriaceae, with species Methanosphaera sp. ISO3-F5, Methanobrevibacter sp. SM9, and Methanobrevibacter ruminantium.

Specifically, at the order level, no significant difference was observed among the four treatments in terms of Methanobacteriales and Methanomicrobiales. However, Methanobacteriales was relatively more abundant in the M3 treatment (0.677) when compared with the control (0.582), M6 (0.615), and M9 (0.606) treatments. At the genus level, the Methanocorpusculum was the third most abundant genus with an average value of $15.0 \%, 6.5 \%, 14.2 \%$, and $9.9 \%$ for the control, M3, M6, and M9 treatments, respectively. Similar values were obtained for Methanobrevibacter among the 4 treatments, whereas the abundance of Methanosphaera was significantly higher in the M3 and M9 treatments (0.297 and 0.293 , respectively, $p<0.05$ ). There was no significant difference between the control and M6 group or between M3 and M9 groups. The species abundance of Methanosphaera sp. ISO3-F5 was significantly higher in the M3 and M9 groups (0.297 and 0.291, respectively) than in the control and M6 groups (0.191 and 0.215 , respectively, $p<0.05)$, but no significant difference was found between the control and M6 groups or between the M3 and M9 groups. The abundance of Methanobrevibacter ruminantium was significantly higher in the control than in the other three groups $(p<0.05)$, but there was no difference among the M3, M6 and M9 group. In addition, values for Methanobrevibacter SM9 were similar across the four groups but accounted for less than $10 \%$ of the total species in each group. 
Table 4. Effects of supplementation of Moringa oleifera rachises and twigs on the relative abundance of fecal methanogenic archaea based on $m c r$ A gene sequences of lactating Holstein dairy cows ${ }^{1}$.

\begin{tabular}{|c|c|c|c|c|c|c|}
\hline \multirow{2}{*}{ Item } & \multicolumn{4}{|c|}{ Treatment } & \multirow{2}{*}{ SEM $^{2}$} & \multirow{2}{*}{$p$-Value } \\
\hline & Control & M3 & M6 & M9 & & \\
\hline \multicolumn{7}{|l|}{ Phylum } \\
\hline Euryarchaeota & 0.734 & 0.743 & 0.757 & 0.705 & 0.022 & 0.883 \\
\hline Uncultured rumen archaea & 0.216 & 0.150 & 0.213 & 0.272 & 0.016 & 0.456 \\
\hline Unclassified & $0.051 \mathrm{ab}$ & $0.108 \mathrm{a}$ & $0.03 \mathrm{ab}$ & $0.023 b$ & 0.015 & 0.172 \\
\hline \multicolumn{7}{|l|}{ Order } \\
\hline Methanobacteriales & 0.582 & 0.677 & 0.615 & 0.606 & 0.023 & 0.561 \\
\hline Methanomicrobiales & 0.150 & 0.065 & 0.142 & 0.099 & 0.026 & 0.676 \\
\hline Uncultured rumen archaea & 0.216 & 0.150 & 0.213 & 0.272 & 0.016 & 0.456 \\
\hline \multicolumn{7}{|l|}{ Family } \\
\hline Methanobacteriaceae & 0.582 & 0.677 & 0.615 & 0.606 & 0.023 & 0.561 \\
\hline Methanocorpusculaceae & 0.150 & 0.065 & 0.142 & 0.099 & 0.026 & 0.676 \\
\hline Uncultured rumen archaea & 0.216 & 0.150 & 0.213 & 0.272 & 0.016 & 0.456 \\
\hline \multicolumn{7}{|l|}{ Genus } \\
\hline Methanobrevibacter & 0.391 & 0.380 & 0.400 & 0.315 & 0.026 & 0.698 \\
\hline Methanosphaera & $0.191 b$ & $0.297 a$ & $0.215 b$ & $0.291 \mathrm{a}$ & 0.016 & 0.016 \\
\hline Methanocorpusculum & 0.150 & 0.065 & 0.142 & 0.099 & 0.026 & 0.676 \\
\hline Uncultured rumen archaea & 0.216 & 0.150 & 0.213 & 0.272 & 0.016 & 0.456 \\
\hline \multicolumn{7}{|l|}{ Species } \\
\hline Unclassified Methanobrevibacter & 0.274 & 0.279 & 0.281 & 0.172 & 0.031 & 0.569 \\
\hline Methanosphaera sp. ISO3-F5 & $0.191 b$ & $0.297 a$ & $0.215 b$ & $0.291 \mathrm{a}$ & 0.016 & 0.016 \\
\hline Unclassified Methanocorpusculum & 0.150 & 0.065 & 0.142 & 0.099 & 0.026 & 0.676 \\
\hline Uncultured rumen archaea & 0.216 & 0.150 & 0.213 & 0.272 & 0.026 & 0.456 \\
\hline Methanobrevibacter sp. SM9 & 0.038 & 0.060 & 0.065 & 0.080 & 0.007 & 0.258 \\
\hline Methanobrevibacter ruminantium & $0.078 \mathrm{a}$ & $0.041 b$ & $0.054 b$ & $0.062 b$ & 0.014 & 0.035 \\
\hline Unclassified & 0.051 & 0.108 & 0.030 & 0.023 & 0.015 & 0.172 \\
\hline
\end{tabular}

\section{Discussion}

\subsection{Feed Intake, Milk Yield and Composition}

Application of agricultural by-products in the ruminant production system has been extensively investigated because of their relatively high biomass yield and low cost. In this research, the production, and fecal methanogenic archaea were examined when lactating dairy cows were subjected to different levels of supplementation of M. oleifera in the diet. The milk fat content in the M6 treatment was significantly higher than that in the control and M3 treatments, although M6 treatment had relatively higher values of milk yield and ECM. Several consistent results were reported previously that supplementation of $M$. oleifera enhanced milk yield and milk composition. For example, Cohen-Zinder et al. [15] found a significant increase in milk yield, milk fat and protein content in lactating cows offered an M. oleifera diet. Azzaz et al. [3] reported that milk and total solid yield increased by 11.3 and $17.7 \%$ in lactating ewes fed a supplement of $15 \mathrm{~g} / \mathrm{kg}$ DM M. oleifera. This positive effect of M. oleifera on production performance can be attributed to improved feed intake, apparent nutrient digestibility, and ruminal fermentation conditions [4,15]. Moderate concentrations of phenolics and tannins in M. oleifera exhibited antioxidant and antimicrobial properties, which have beneficial effects in productive ruminants [16]. Aerts et al. [17] reported that ruminal methanogenesis would be inhibited by phenolics and tannins, which leading to repartition of consumed energy in $\mathrm{CH}_{4}$ and milk 
production. This was in agreement with the results of Shaani et al. [7] that improved fat yield and ECM production efficiency resulted from inhibition of $\mathrm{CH}_{4}$ production by ruminal methanogenic bacteria.

\subsection{Fecal Methanogenic Composition and Dynamics}

The composition and function of ruminal methanogens have been studied in great detail, whereas less is known in the lower gastrointestinal tract (GIT) of ruminants [18]. Previous research showed relationships between methanogens in feces and those present in the pregastric compartments $[19,20]$. In the present study, the functional mcrA gene sequencing technique was used, and the results revealed the presence of Methanobrevibacter, Methanosphaera, and Methanocorpusculum in the feces of lactating dairy cows. These results were consistent with previous studies that detected two phyla and six genera in the feces of multiparous dairy cows, whereas fecal mcrA sequences had the closest similarity to Methanocorpusculum, Methanobacterium, and Methanobrevibacter species [9]. Jin et al. [9] found that fecal archaeal community was predominated by Methanobrevibacter ( $86.9 \%$ of the total sequence reads) and Methanocorpusculum (10.4\%). A bTEFAP pyrosequencing study reported the dominant methanogens of Methanobrevibacter, Methanophaera, and Methanobacteriaceae in the hindgut of goats [21]. In addition, Mohammadzadeh et al. [10] suggested that the fermentation characteristics as digesta pass from the rumen into the small intestine and out of the animal would affect methanogen diversity. The sequencing technique may also influence the results, although the morA gene-based approach was thought to be comparable to the $16 \mathrm{~S}$ rRNA gene for phylogenetic studies.

Different from previous studies, however, the present study demonstrated that Methanobrevibacter sequence made up approximately 35\% of the total. Guzman et al. [22] hardly detected Methanobrevibacter in the feces of calves in the first 3 days after birth. In mature cows, Methanobrevibacter represented $62 \%$ of the rumen archaea, and they were among the most important and dominant archaea in the rumen fluid. A higher percentage was also found in the hindgut of goats with Methanobrevibacter accounting for $74.8 \%$ of the total sequenced reads, while Jin et al. [9] reported that Methanobrevibacter was the dominant phylotype at the genus level accounting for over $86 \%$ of the total sequence reads. These results indicated that the presence and abundance of Methanobrevibacter may be influenced by dietary composition, enteric fermentation, and even environmental factors.

At the genus level, the relative abundance of Methanosphaera and Methanocorpusculum was generally around $20 \%$ and $15 \%$ in the fecal sample of dairy cows, higher than previously reported from the rumen and fecal samples of ruminants [19]. For example, Liu et al. [19] did not detect Methanocorpusculum in the rumen but made up only $2 \%$ of the archaeal community in the feces of sheep. Jin et al. [9] reported a very low content of Methanosphaera in the feces of lactating cows $(0.8 \%)$. The great diversity of the fecal microbiota can be attributed to various factors such as animal breeds, diet sources, and composition.

\subsection{Effect of Moringa Oleifera Supplementation on Fecal Methanogenic Archaea}

A range of studies reported that the fecal microbial relative abundance and composition were affected by types of diet or different dietary supplementations [23-25]. For example, the fecal microbial community structure was significantly changed as cattle were fed either high-grain diets or high-forage diets [24]. In our mcrA gene-based sequencing study of the methanogenic archaeal community in the feces of lactating cows, the richness indexes remained similar when M. oleifera was added at different levels to the diet. However, the Simpson diversity index was significantly lower compared to the control treatment. Changes in the fecal methanogen diversity might be dependent on nutrient contents and the fermentation profile of the fecal samples as a result of secondary metabolites from M. oleifera, similar to the alteration of the ruminal environment and microbial activity when $M$. oleifera was fed to ruminants [1,9]. For example, previous results showed that feeding M. oleifera plant improved nutrient digestibility and increased SCFA concentration in the rumen of goat, which resulted in the growth of propionate-producing bacterial species and inhibition of $\mathrm{CH}_{4}$-producing archaea [26]. The high protein (241-277 g/kg DM) and polyphenol content make M. oleifera a high-quality feed resource [27]. Bioactive products such as saponins $(80 \mathrm{~g} / \mathrm{kg})$ and tannins $(12 \mathrm{~g} / \mathrm{kg})$ in M. oleifera leaves have an antimicrobial 
function and play a key role in improving nutrient digestibility and fermentation efficiency [28,29]. When steers were supplemented with up to $30 \mathrm{~g} /$ day tea saponin, daily $\mathrm{CH}_{4}$ emission (g/day) was reduced by $18 \%$, and yield $\left(\mathrm{CH}_{4} / \mathrm{DM}\right.$ intake, $\left.\mathrm{g} / \mathrm{kg}\right)$ was reduced by $22 \%$ [30]. In the present study, as demonstrated in our previous experiment, the calculated saponin intake was $144 \mathrm{~g} /$ day when $9 \%$ of $M$. oleifera was included in the diet. We thus assumed that the composition and distribution of methanogenic archaea changed along the gastrointestinal tract, and methanogenesis and $\mathrm{CH}_{4}$ emissions would be inhibited by such a large amount of saponin intake. However, feeding saponin-containing Yucca schidigera and Quillaja saponaria powder (10 g/ $\mathrm{kg}$ DM) differed little in $\mathrm{CH}_{4}$ emission (g/day) and yield $\left(\mathrm{CH}_{4}-\mathrm{E} / \mathrm{GE}\right.$ intake) from the basal diet [31]. This discrepancy of $\mathrm{CH}_{4}$ reduction may be attributed to the source and the actual saponin content. Further research is needed to compare responses when similar saponin sources or supplementation levels are used.

When M. oleifera was added to the diet, Methanosphaera and Methanosphaera sp. ISO3-F5 increased in abundance but Methanobrevibacter ruminantium decreased compared with the control group. Methanobrevibacter ruminantium is a strict anaerobe that can produce $\mathrm{CH}_{4}$ from $\mathrm{H}_{2}, \mathrm{CO}_{2}$, and formate and has a close syntrophic association with protozoa [32]. Secondary metabolites from M. oleifera such as saponins and tannins have antiprotozoal properties that affect cell membrane integrity [33]. Soliva et al. [34] found that approximately $30 \%$ of ciliate protozoa concentration was reduced when extracted M. oleifera was added in vitro experiment. This result was in accordance with the inhibitory effect of saponin on ruminal ciliate protozoa population in cattle or sheep [35]. In line with a range of in vivo and in vitro experiments adding different sources and levels of secondary metabolites from M. oleifera, Methanosphaera sp. ISO3-F5 increased as levels of M. oleifera increased. As one of the main methylotrophic methanogens, Methanosphaera sp. ISO3-F5 was found to be associated with different bacteria including members of Lachnospiraceae [36]. Thus, it would be interesting to examine the pectin content of M. oleifera to see its influence on Methanosphaera sp. ISO3-F5 abundance. In addition, more future work will be needed to investigate the interaction between some specific methanogens and ruminal fermentation conditions, which may help for a better understanding of rumen microbial metabolic function and development of $\mathrm{CH}_{4}$ mitigation approaches.

\section{Conclusions}

This study demonstrated that different supplementation levels of Moringa oleifera in the diet achieved similar feed intake, milk production, but adding 6\% of Moringa oleifera improved milk fat content. The fecal methanogenic archaea diversity changed as the increased abundance of the Methanosphaera genus and Methanosphaera sp. ISO3-F5 species was induced by secondary metabolites of Moringa oleifera in the diet. This study provided some basic information on the utilization of Moringa oleifera as forage resources for dairy cows, and helped to elucidate the interaction between methanogens and other microbes, regulation of microbial metabolic function and methane emissions.

Author Contributions: Conceptualization, Q.D.; methodology, L.D.; data curation, T.Z.; writing一original draft preparation, L.D.; writing_review and editing, Q.D.; visualization, L.D.; supervision, Q.D; project administration, Q.D.; funding acquisition, L.D. and Q.D.

Funding: This research was funded by the Program of International S and T Cooperation (grant number 2016YFE0109000), the National Science Foundation for Young Scientists of China (grant number 31802085), the National Key Research and Development Program of China (grant number 2017YFF0211702), and Young Scientist Lifting Project (2017-2019).

Acknowledgments: The authors thank colleagues in Feed Research Institute and Century Love International Investment Group Co. Ltd., Beijing for providing kind assistance in animal experiments, sample processing, and data collection. The authors would like to thank reviewers for their suggestions and comments on this work.

Conflicts of Interest: The authors declare no conflict of interest. 


\section{References}

1. Kholif, A.E.; Gouda, G.A.; Anele, U.Y.; Galyean, M.L. Extract of Moringa oleifera leaves improves feed utilization of lactating Nubian goats. Small Rumin. Res. 2018, 158, 69-75. [CrossRef]

2. Zhang, T.T.; Si, B.W.; Deng, K.D.; Tu, Y.; Zhou, C.L.; Diao, Q.Y. Effects of feeding a Moringa oleifera rachis and twig preparation to dairy cows on their milk production and fatty acid composition, and plasma antioxidants. J. Sci. Food Agric. 2018, 98, 661-666. [CrossRef] [PubMed]

3. Azzaz, H.H.; Farahat, E.S.A.; Morsy, T.A.; Aziz, H.A.; Hadhoud, F.I.; Abd-Alla, M.S. Moringa oleifera and Echinacea purpurae as supplements for Rhamani lactating ewe's diets and their effect on rumen characteristics, nutrients digestibility, blood parameters, milk production, composition and its fatty acid profile. Asian J. Anim. Vet. Adv. 2016, 11, 684-692. [CrossRef]

4. Mendieta-Araica, B.; Sporndly, R.; Reyes-Sanchez, N.; Sporndly, E. Moringa (Moringa oleifera) leaf meal as a source of protein in locally produced concentrates for dairy cows fed low protein diets in tropical areas. Livest. Sci. 2011, 137, 10-17. [CrossRef]

5. Zeng, B.; Sun, J.J.; Chen, T.; Sun, B.L.; He, Q.; Chen, X.Y.; Zhang, Y.L.; Xi, Q.Y. Effects of Moringa oleifera silage on milk yield, nutrient digestibility and serum biochemical indexes of lactating dairy cows. J. Anim. Physiol. Anim. Nutr. 2018, 1, 75-81. [CrossRef]

6. Sarkar, S.; Mohini, M.; Nampoothiri, V.M.; Mondal, G.; Pandita, S.; Mahesh, M.S. Effect of supplementation of Moringa oleifera leaves on in vitro methane emissions and rumen fermentation on roughage based ration. In Proceedings of the XVI Biennial Animal Nutrition Conference on Innovative Approaches for Animal Feeding and Nutritional Research, Karnal, India, 6-8 February 2016.

7. Shaani, Y.; Eliyahu, D.; Mizrahi, I.; Yosef, E.; Ben-Meir, Y.; Nikbachat, M.; Solomon, R.; Mabjeesh, S.J.; Miron, J. Effect of feeding ensiled mixture of pomegranate pulp and drier feeds on digestibility and milk performance in dairy cows. J. Dairy Res. 2016, 1, 35-41. [CrossRef] [PubMed]

8. Daquiado, A.R.; Cho, K.M.; Kim, T.Y.; Kim, S.C.; Chang, H.H.; Lee, Y.B. Methanogenic archaea diversity in Hanwoo (Bos taurus coreanae) rumen fluid, rectal dung, and barn floor manure using a culture-independent method based on mcrA gene sequence. Anaerobe 2014, 27, 77-81. [CrossRef]

9. Jin, D.X.; Kang, K.; Wang, H.Z.; Wang, Z.S.; Xue, B.; Wang, L.Z.; Xu, F.; Peng, Q.H. Effects of dietary supplementation of active dried yeast on fecal methanogenic archaea diversity in dairy cows. Anaerobe 2017, 44, 78-86. [CrossRef] [PubMed]

10. Mohammadzadeh, H.; Yáñez-Ruiz, D.R.; Martínez-Fernandez, G. Molecular comparative assessment of the microbial ecosystem in rumen and faeces of goats fed alfalfa hay alone or combined with oats. Anaerobe 2014, 29, 52-58. [CrossRef]

11. AOAC International. Official Methods of Analysis, 20nd ed.; AOAC International: Rockville, MD, USA, 2016.

12. Luton, P.E.; Wayne, J.M.; Sharp, R.J.; Riley, P.W. The morA gene as an alternative to $16 \mathrm{~S}$ rRNA in the phylogenetic analysis of methanogen populations in landfill. Microbiol. 2002, 148, 3521-3530. [CrossRef]

13. Amato, K.R.; Yeoman, C.J.; Kent, A.; Righini, N.; Carbonero, F.; Estrada, A.; Gaskins, H.R.; Stumpf, R.M.; Yildirim, S.; Torralba, M.; et al. Habitat degradation impacts black howler monkey (Alouatta pigra) gastrointestinal microbiomes. ISME J. 2013, 7, 1344-1353. [CrossRef] [PubMed]

14. Oliveros, J.C. VENNY. An Interactive tool for Comparing Lists with Venn Diagrams; BioinfoGP of CNB-CSIC: Madrid, Spain, 2007.

15. Cohen-Zinder, M.; Leibovich, H.; Vaknin, Y.; Sagi, G.; Shabtay, A.; Ben-MEIR, Y.; Nikbachat, M.; Protnik, Y.; Yishay, M.; Miron, J. Effect of feeding lactating cows with ensiled mixture of Moringa oleifera, wheat hay and molasses, on digestibility and efficiency of milk production. Anim. Feed Sci. Technol. 2016, 211, 75-83. [CrossRef]

16. Verma, A.R.; Vijayakumar, M.; Mathela, C.S.; Rao, C.V. In vitro and in vivo antioxidant properties of different fractions of Moringa oleifera leaves. Food Chem. Toxicol. 2009, 47, 2110-2196. [CrossRef]

17. Aerts, R.J.; Barry, T.N.; McNabbm, W.C. Polyphenols and agriculture: Beneficial effects of proanthocyanidins in forages. Agric. Ecosyst. Environ. 1999, 75, 1-12. [CrossRef]

18. Faulkner, M.J.; Wenner, B.A.; Solden, L.M.; Weiss, W.P. Source of supplemental dietary copper, zinc, and manganese affects fecal microbial relative abundance in lactating dairy cows. J. Dairy Sci. 2017, 100, 1037-1044. [CrossRef] [PubMed] 
19. Liu, C.; Zhu, Z.P.; Liu, Y.F.; Guo, T.J.; Dong, H.M. Diversity and abundance of the rumen and fecal methanogens in Altay sheep native to Xinjiang and the influence of diversity on methane emissions. Arch. Microbiol. 2012, 194, 353-361. [CrossRef]

20. Zhou, M.; Chen, Y.H.; Griebel, P.J.; Guan, L.L. Methanogen prevalence throughout the gastrointestinal tract of pre-weaned dairy calves. Gut Microbes 2014, 5, 628-638. [CrossRef]

21. Min, B.R.; Solaiman, S.; Shange, R.; Eun, J.S. Gastrointestinal bacterial and methanogenic archaea diversity dynamics associated with condensed tannin-Containing pine bark diet in goats using 16S rDNA amplicon pyrosequencing. Int. J. Microbiol. 2014, 4, 1-11. [CrossRef]

22. Guzman, C.E.; Bereza-Malcolm, L.T.; Groef, B.D.; Franks, A.E. Presence of selected methanogens, fibrolytic bacteria, and proteobacteria in the gastrointestinal tract of neonatal dairy calves from birth to 72 hours. PLoS ONE 2015, 7, e0133048. [CrossRef]

23. Dowd, S.E.; Callaway, T.R.; Wolcott, R.D.; Sun, Y.; McKeehan, T.; Hagevoort, R.G.; Edrington, T.S. Evaluation of the bacterial diversity in the feces of cattle using $16 \mathrm{~S}$ rDNA bacterial tag-encoded FLX amplicon pyrosequencing (bTEFAP). BMC Microbiol. 2008, 8, 125. [CrossRef]

24. Shanks, O.C.; Kelty, C.A.; Archibeque, S.; Jenkins, M.; Newton, R.J.; McLellan, S.L.; Huse, S.M.; Sogin, M.L. Community structures of fecal bacteria in cattle from different animal feeding operations. Appl. Environ. Microbiol. 2011, 77, 2992-3001. [CrossRef]

25. Durso, L.M.; Wells, J.E.; Harhay, G.P.; Rice, W.C.; Kuehn, L.; Bono, J.L.; Shackelford, S.; Wheeler, T.; Smith, T.P.L. Comparison of bacterial communities in faeces of beef cattle fed diets containing corn and wet distillers' grain with solubles. Lett. Appl. Microbiol. 2012, 55, 109-114. [CrossRef] [PubMed]

26. Wallace, R.J.; McEwan, N.R.; McIntosh, F.M.; Teferedegne, B.; Newbold, C.J. Natural products as manipulators of rumen fermentation. Asian Austral. J. Anim. Sci. 2002, 15, 1458-1468. [CrossRef]

27. Elghandour, M.M.Y.; Vallejo, L.H.; Salem, A.Z.M.; Mellado, M.; Camacho, L.M.; Cipriano, M.; Olafadehan, O.A.; Olivares, J.; Rogas, S. Moringa oleifera leaf meal as an environmental friendly protein source for ruminants: Biomethane and carbon dioxide production, and fermentation characteristics. J. Clean. Prod. 2017, 165, 1229-1238. [CrossRef]

28. Ferreira, P.M.P.; Farias, D.F.; de Abreu Oliveira, J.T.; de Fátima Urano Carvalho, A. Moringa oleifera: Bioactive compounds and nutritional potential. Revista de Nutrição 2008, 21, 431-437. [CrossRef]

29. Teixeira, E.M.B.; Carvalho, M.R.B.; Neves, V.A.; Silva, M.A.; Arantes-Pereira, L. Chemical characteristics and fractionation of proteins from Moringa oleifera Lam. leaves. Food Chem. 2014, 147, 51-54. [CrossRef]

30. Ramírez-Restrepoa, C.A.; Tan, C.; O’Neill, C.J.; López-Villalobos, N.; Padmanabha, J.; Wang, J.K.; McSweeney, C.S. Methane production, fermentation characteristics, and microbial profiles in the rumen of tropical cattle fed tea seed saponin supplementation. Anim. Feed. Sci. Technol. 2016, 216, 58-67. [CrossRef]

31. Holtshausen, L.; Chaves, A.V.; Beauchemin, K.A.; McGinn, S.M.; McAllister, T.A.; Odongo, N.E.; Cheeke, P.R.; Benchaar, C. Feeding saponin-containing Yucca schidigera and Quillaja saponaria to decrease enteric methane production in dairy cows. J. Dairy Sci. 2009, 92, 2809-2821. [CrossRef] [PubMed]

32. Finlay, B.J.; Esteban, G.; Clarke, K.J.; Williams, A.G.; Embley, T.M.; Hirt, R.P. Some rumen ciliates have endosymbiotic methanogens. FEMS Microbiol. Lett. 1994, 117, 157-162. [CrossRef]

33. Morgavi, D.P.; Martin, C.; Jouany, J.P.; Ranilla, M.J. Rumen protozoa and methanogenesis: Not a simple cause-effect relationship. Br. J. Nutr. 2012, 107, 388-397. [CrossRef]

34. Soliva, C.R.; Kreuzer, M.; Foidl, N.; Foidl, G.; Machnüller, A.; Hess, H.D. Feeding value of whole and extracted Moringa oleifera leaves for ruminants and their effects on ruminal fermentation in vitro. Anim. Feed Sci. Technol. 2005, 118, 47-62. [CrossRef]

35. Zhou, M.; Hernandez-Sanabria, E.; Guan, L.L. Assessment of the microbial ecology of ruminal methanogens in cattle with different feed efficiency. Appl. Environ. Microbiol. 2009, 75, 6524-6533. [CrossRef] [PubMed]

36. Henderson, G.; Cox, F.; Ganesh, S.; Jonker, A.; Young, W.; Janssen, P.H. Rumen microbial community composition varies with diet and host, but a core microbiome is found across a wide geographical range. Sci. Rep. 2015, 5, 14567. [CrossRef] [PubMed]

(C) 2019 by the authors. Licensee MDPI, Basel, Switzerland. This article is an open access article distributed under the terms and conditions of the Creative Commons Attribution (CC BY) license (http://creativecommons.org/licenses/by/4.0/). 